\title{
Errorless learning of everyday tasks in people with dementia
}

This article was published in the following Dove Press journal:

Clinical Interventions in Aging

12 September 2013

Number of times this article has been viewed

\section{Maartje ME de Werd ${ }^{1,2,5}$ \\ Daniëlle Boelen ${ }^{1-3}$ \\ Marcel GM Olde Rikkert ${ }^{2,4}$ \\ Roy PC Kessels 1,2,4}

'Radboud University Nijmegen Medical Centre, Department of Medical Psychology, ${ }^{2}$ Radboud University Nijmegen Medical Centre, Department of Geriatric Medicine and Radboud Alzheimer Centre, Nijmegen, ${ }^{3}$ Rehabilitation Medical Centre, Groot Klimmendaal, Arnhem, ${ }^{4}$ Radboud University Nijmegen, Donders Institute for Brain, Cognition and Behaviour, Nijmegen, ${ }^{5}$ VieCuri Hospital, Department of Medical Psychology, Venlo, the Netherlands
Correspondence: Roy PC Kessels Radboud University Nijmegen Medical Centre, Department of Medical Psychology and Radboud Alzheimer Centre, PO Box 9101 (internal post 925), 6500 HB Nijmegen, the Netherlands Tel +3I 243666196

Email r.kessels@mps.umcn.nl
Abstract: Errorless learning (EL) is a principle used to teach new information or skills to people with cognitive impairment. In people with dementia, EL principles have mostly been studied in laboratory tasks that have little practical relevance for the participants concerned, yet show positive effects. This is the first paper to exclusively review the literature concerning the effects of EL on the performance of useful everyday tasks in people with dementia. The role of factors such as type of dementia, type of task, training intensity, EL elements, outcome measures, quality of experimental design, and follow-up are discussed. The results indicate that, compared with errorful learning (EF) or no treatment, EL is more effective in teaching adults with dementia a variety of meaningful daily tasks or skills, with gains being generally maintained at follow-up. The effectiveness of EL is highly relevant for clinical practice because it shows that individuals with dementia are still able to acquire meaningful skills and engage in worthwhile activities, which may potentially increase their autonomy and independence, and ultimately their quality of life, as well as reduce caregiver burden and professional dependency. Suggestions for future research are given, along with recommendations for effective EL-based training programs, with the aim of developing a clinical manual for professionals working in dementia care.

Keywords: dementia, implicit learning, occupational therapy, errorless learning, review, everyday activities

\section{Introduction}

In dementia, most notably dementia due to Alzheimer's disease, memory impairments are among the most prominent cognitive deficits. These impairments predominantly affect episodic memory, with detrimental effects on daily life functioning for those suffering from the condition, inevitably severely compromising their autonomy and quality of life. If people with dementia can (re)learn relevant activities and skills, this may improve their sense of competence and foster their ability to (partly) maintain their independence, as well as reduce the burden on professional and nonprofessional caregivers.

Nonpharmacologic interventions, such as cognitive rehabilitation programs, that aim to facilitate performance and optimize the (re)learning of skills rather than restore the impaired function, have been found to be effective. ${ }^{1,2}$ Typically, in patients with dementia, such therapies focus on maintaining quality of life despite the presence of deficits that may even progress over time. ${ }^{1,3,4}$ Existing cognitive rehabilitation programs rely on structured feedback and repetition, as well as on the use of cognitive strategies and external aids, such as calendars or notebooks, to help optimize functioning. In their meta-analysis, Sitzer et $\mathrm{al}^{5}$ concluded that, in general, cognitive rehabilitation 
may be effective for improving learning, memory, executive functioning, performance of activities of daily living, general cognitive problems, and ameliorating depression in people with Alzheimer's disease. Errorless learning (EL) is one such cognitive rehabilitation strategy that has been gaining interest over the last two decades in the field of dementia care. ${ }^{4}$

In rehabilitation, the principle of EL is used as an instructional method for individuals with compromised memory and executive functions and may involve any intervention aimed at reducing the number of errors throughout the various stages of learning. This error reduction may be achieved by any combination of graded tasks where the task at hand is broken down into small steps, immediate error correction, encouraging participants not to guess, modeling the task steps, fading cues and prompts when steps are successfully performed (vanishing cues), or rehearsal of the retrieval of information that is taught with increasing time intervals (spaced retrieval). ${ }^{4}$ Terrace first introduced EL in the early 1960 s in an animal study. ${ }^{6}$ His experiment involved the training of pigeons to discriminate between a red and a green key using both an EL and an errorful approach (EF), with learning in the EL condition resulting in superior memory performance. Because this implies that the reduction of errors facilitates the learning of behavior or skills, Baddeley ${ }^{7}$ put EL forward as a potential learning aid to teach amnesic (new) information 30 years later, suggesting that EL addresses the (relatively) spared implicit memory functions in people with amnesia. ${ }^{4,8}$ The rationale behind EL is that explicit memory is responsible for recognizing and correcting the errors that are made during learning. In people with deficits in explicit memory, such as individuals with Alzheimer's disease, these errors may not be recognized as such, and are therefore not corrected but instead implicitly consolidated into long-term memory. To investigate this hypothesis, Baddeley and Wilson ${ }^{8}$ compared $^{-}$ EF and EL using a word stem task in adults with memory impairments of mixed etiology (including dementia). Their amnesic participants showed significantly better learning and less forgetting in the EL condition.

Since then, EL has been used in interventions aimed at memory and executive deficits resulting from, among other causes, traumatic brain injury, Korsakoff's syndrome, stroke, or schizophrenia, ${ }^{4,9-15}$ as well as in elderly populations with mild, moderate, and severe memory disorders (ie, dementia). ${ }^{4}$ Grandmaison and Simard ${ }^{16}$ reviewed various memory stimulation and remediation programs for persons with Alzheimer's disease and found the interventions that incorporated EL to be effective.
Most of the EL efficacy studies that have been reviewed so far used laboratory tasks, with positive effects being reported for controlled experimental manipulations in various patient samples. However, it remains unclear how well these results would convey to a more natural situation (ie, clinical practice or the home) with tasks that bear true relevance to patients. Moreover, most studies did not investigate the long-term effects of EL in people with dementia.

The objective of this review therefore is to evaluate critically the effectiveness of EL in teaching people with dementia meaningful activities of daily living. These refer to all activities, tasks, or skills that have some relevance in everyday life of the individual patient that may enhance his or her autonomy. One should think of (re)learning the names of familiar people, (re)training leisure activities, and (re) gaining communication skills (eg, preparing to go out for a walk, learning to use an MP3 player, or writing an email). Also, we examine the longevity of the effects reported (ie, the follow-up results) and provide recommendations about the practical feasibility and application of EL in clinical practice.

\section{Materials and methods}

Potentially relevant studies were identified by searching the PubMed, PsychInfo, and Web of Science databases until April 12, 2013, using combinations of the search terms: "errorless learning", "Alzheimer", “dementia", "everyday activities", "daily life activities", "everyday memory problems", "everyday life functioning", "skill learning", and "everyday skills learning". In addition, reference lists from the retrieved articles were screened to identify additional papers. The PsycBITE Internet site was also consulted. Articles were included for review if they met the following criteria:

1. The study sample(s) comprise(s) people with a diagnosis of dementia. Participants in the intervention studies have cognitive impairments resulting from neurodegenerative diseases, ie, a diagnosis of Alzheimer's disease, semantic dementia, or vascular dementia. Participants fulfill either the criteria for dementia as outlined in the Diagnostic and Statistical Manual of Mental Disorder (DSM-IV-TR), ${ }^{17}$ or disease-specific criteria such as those for Alzheimer's dementia as formulated by the National Institute of Neurological and Communicative Diseases and the Stroke-Alzheimer's Disease and Related Disorders Association, ${ }^{18}$ the criteria for vascular dementia adhered to by the National Institute of Neurological Disorders and 
Stroke-Association Internationale pour la Recherche et l'Enseignement en Neurosciences, ${ }^{19}$ or criteria for semantic dementia or frontotemporal dementia. ${ }^{20-22}$ In addition, studies were included if diagnoses were based on historic information, neurologic examination, neuropsychologic assessment, and supported by findings on structural and functional imaging.

2. Tasks are relevant to daily life and meaningful to the participants. Intervention studies evaluate the effects of EL in tasks that are potentially useful for individuals with dementia to (re)learn, contributing to preservation or enhancing their autonomy.

3. Error-reduction principles are applied. The intervention studies address the (re)learning of meaningful activities of daily living by means of EL. The actual application of EL principles shows a large variation in the literature and may include a combination of teaching principles, provided that the amount of errors made during the acquisition and/or retrieval phases of learning is kept to a minimum, or is prevented altogether. In Table 1, various error-reducing methods are presented.

Table I Error-reducing methods applied in the studies reviewed

\begin{tabular}{|c|c|}
\hline Method & Definition \\
\hline No guessing & $\begin{array}{l}\text { The participant is encouraged not to guess to prevent } \\
\text { errors. Either the correct response is immediately } \\
\text { offered, after which the participant is asked to repeat } \\
\text { it, or the correct response is provided in case of } \\
\text { hesitation or uncertainty. }\end{array}$ \\
\hline $\begin{array}{l}\text { Stepwise } \\
\text { approach }\end{array}$ & The task is mastered step by step. \\
\hline Modeling & $\begin{array}{l}\text { The therapist demonstrates to the participant how } \\
\text { each step is to be performed. The participant is first } \\
\text { invited to repeat and master each step, before he/ } \\
\text { she is asked to execute the whole task unprompted, } \\
\text { independently, and without errors. }\end{array}$ \\
\hline $\begin{array}{l}\text { Verbal } \\
\text { instruction }\end{array}$ & $\begin{array}{l}\text { The participant is explicitly explained what to do } \\
\text { in each of the task steps or what is to be repeated. }\end{array}$ \\
\hline $\begin{array}{l}\text { Visual } \\
\text { instruction }\end{array}$ & $\begin{array}{l}\text { The therapist may give the participant any visual cue or } \\
\text { prompt to help guide the participant through the task, } \\
\text { such as a checklist with pictograms, a written action plan, } \\
\text { or colored stickers to indicate a specific object or place. }\end{array}$ \\
\hline $\begin{array}{l}\text { Vanishing } \\
\text { cues }\end{array}$ & $\begin{array}{l}\text { Targets are presented and cues gradually withheld } \\
\text { after successful recall trials until the participant is able } \\
\text { to give the correct response in the absence of cues. }\end{array}$ \\
\hline $\begin{array}{l}\text { Spaced } \\
\text { retrieval }\end{array}$ & $\begin{array}{l}\text { The participant is asked to recall (new) information } \\
\text { after increasing delays. The therapist provides the } \\
\text { correct response when the participant hesitates or } \\
\text { indicates to not know the correct response. The recall } \\
\text { interval is then reduced until the participant is able } \\
\text { to reproduce the desired response, after which the } \\
\text { interval is increased again until the participant is able to } \\
\text { give the correct response after the longest interval. }\end{array}$ \\
\hline
\end{tabular}

4. Outcome measures are quantitative and pertain to functioning in daily life. The methodology comprises at least one quantitative outcome measure, eg, the number of correctly performed steps and/or the number of errors made during task performance.

5. The intervention studies are controlled. Studies eligible for review are either group studies with a control group or control condition, comparing EL with another type of learning (ie, EF) or no treatment, or single-case studies (eg, multiple-baseline design, reversal design, or case series). To examine the effectiveness of EL, the following study aspects were scrutinized:

- Type of dementia and severity, based on Mini-Mental State Examination scores (MMSE) ${ }^{23}$ subdivided into four categories: minimal (MMSE $>$ ), ${ }^{23}$ mild (MMSE 18-23), moderate (MMSE 10-17), and severe (MMSE $<10){ }^{24,25}$

- Task type, eg, orientation tasks, familiar face-name associations, operating an electronic device or household appliance, and task novelty, ie, relearning previously known skills or acquiring new ones

- Training intensity in terms of duration and frequency of training sessions

- Training location, eg, at home, in the hospital, or in a residential or nursing home

- (Combinations of) EL elements applied in the intervention(s) evaluated

- Experimental design

- Outcome measures

- Effectiveness

- Maintenance of treatment gains at follow-up (ie, after training had stopped) and (number and nature of) refresher sessions, if provided.

Because samples were small $(\mathrm{n}<12)$ in 24 of the 26 studies reviewed and because the learning procedures varied considerably among studies, we performed a qualitative analysis of the evidence rather than a formal meta-analysis.

\section{Results}

A total of 26 studies reported in 16 research articles were included, each employing some form of EL in teaching patients with dementia activities that they found relevant and meaningful for their daily lives, using error-reduction principles, quantitative outcome measures, and controlled study designs. As one of these studies ${ }^{26}$ described the follow-up assessment of a previous study by Clare et al, ${ }^{27}$ the results of that follow-up study are only described under the heading "Effectiveness and maintenance of treatment gains" and not in the remaining part of the 
Table 2 Studies reviewed that compared the effectiveness of errorless learning and errorful learning or no treatment in people with dementia

\begin{tabular}{|c|c|c|c|c|c|c|}
\hline Study & $\mathbf{n}$ & $\begin{array}{l}\text { MMSE } \\
\text { score }\end{array}$ & $\begin{array}{l}\text { Dementia type } \\
\text { and severity }\end{array}$ & Task type and novelty & $\begin{array}{l}\text { Training intensity: } \\
\text { duration and frequency }\end{array}$ & $\begin{array}{l}\text { Training } \\
\text { location }\end{array}$ \\
\hline Bier et $\mathrm{al}^{28}$ & $\mathrm{I}$ & 26 & Minimal AD & $\begin{array}{l}\text { Use of calendar to reduce } \\
\text { repetitive questioning about } \\
\text { date and calls made to family } \\
\text { New }\end{array}$ & $\begin{array}{l}\text { I.5 hours } \\
\text { Unclear }\end{array}$ & At home \\
\hline Bier et $\mathrm{al}^{28}$ & I & 26 & Minimal AD & $\begin{array}{l}\text { Operating the cassette deck } \\
\text { Familiar }\end{array}$ & $\begin{array}{l}\text { I.5 hours } \\
\text { Twice a week for } 5 \text { months }\end{array}$ & At home \\
\hline Bier et $\mathrm{al}^{28}$ & I & 26 & Minimal AD & $\begin{array}{l}\text { Participating in a social activity } \\
\text { Familiar }\end{array}$ & $\begin{array}{l}\text { I. } 5 \text { hours } \\
\text { Twice a week for } 5 \text { months }\end{array}$ & At home \\
\hline Clare et $\mathrm{al}^{27}$ & $\mathrm{I}$ & 27 & Minimal AD & $\begin{array}{l}\text { Names of members of a social club } \\
\text { Unknown }\end{array}$ & $\begin{array}{l}\text { Unclear } \\
\text { Twice a week (total 2I) } \\
\text { and training at club and } \\
\text { three times daily at home }\end{array}$ & At home \\
\hline Clare et $\mathrm{al}^{34}$ & I & $21-26$ & $\begin{array}{l}\text { Minimal to } \\
\text { mild } A D\end{array}$ & $\begin{array}{l}\text { Familiar face-name associations } \\
\text { Familiar }\end{array}$ & $\begin{array}{l}\text { Unclear } \\
\text { Unclear }\end{array}$ & Unknown \\
\hline Clare et $\mathrm{al}^{34}$ & I & $21-26$ & $\begin{array}{l}\text { Minimal to } \\
\text { mild } A D\end{array}$ & $\begin{array}{l}\text { Personal information } \\
\text { Familiar }\end{array}$ & $\begin{array}{l}\text { Unclear } \\
\text { Unclear }\end{array}$ & Unknown \\
\hline Clare et $\mathrm{al}^{34}$ & I & $2 I-26$ & $\begin{array}{l}\text { Minimal to } \\
\text { mild } A D\end{array}$ & $\begin{array}{l}\text { Use of calendar and memory board } \\
\text { Unknown }\end{array}$ & $\begin{array}{l}\text { Unclear } \\
\text { Unclear }\end{array}$ & Unknown \\
\hline Clare et $\mathrm{al}^{34}$ & I & $21-26$ & $\begin{array}{l}\text { Minimal to } \\
\text { mild AD }\end{array}$ & $\begin{array}{l}\text { Use of a memory aid } \\
\text { Unknown }\end{array}$ & $\begin{array}{l}\text { Unclear } \\
\text { Unclear }\end{array}$ & Unknown \\
\hline Clare et $\mathrm{al}^{26}$ & I & 27 & Minimal AD & $\begin{array}{l}\text { Names of members of a social club } \\
n / a\end{array}$ & $\begin{array}{l}\mathrm{n} / \mathrm{a} \\
\mathrm{n} / \mathrm{a}\end{array}$ & $\mathrm{n} / \mathrm{a}$ \\
\hline Clare et $\mathrm{al}^{35}$ & 12 & $19-29$ & $\begin{array}{l}\text { Minimal to } \\
\text { mild } A D\end{array}$ & $\begin{array}{l}\text { Familiar face-name associations } \\
\text { Familiar }\end{array}$ & $\begin{array}{l}\text { Unclear } \\
6 \text { sessions, (total 8) } \\
\text { and practice at home until } \\
\text { the one-month follow-up }\end{array}$ & Unknown \\
\hline Clare et $\mathrm{al}^{29}$ & I & 24 & Minimal AD & $\begin{array}{l}\text { Names of members } \\
\text { of a support group } \\
\text { Unknown }\end{array}$ & $\begin{array}{l}\text { Unclear } \\
\text { Between sessions practicing } \\
\text { each set of names once daily } \\
\text { at home for } 3 \text { months }\end{array}$ & Unknown \\
\hline
\end{tabular}




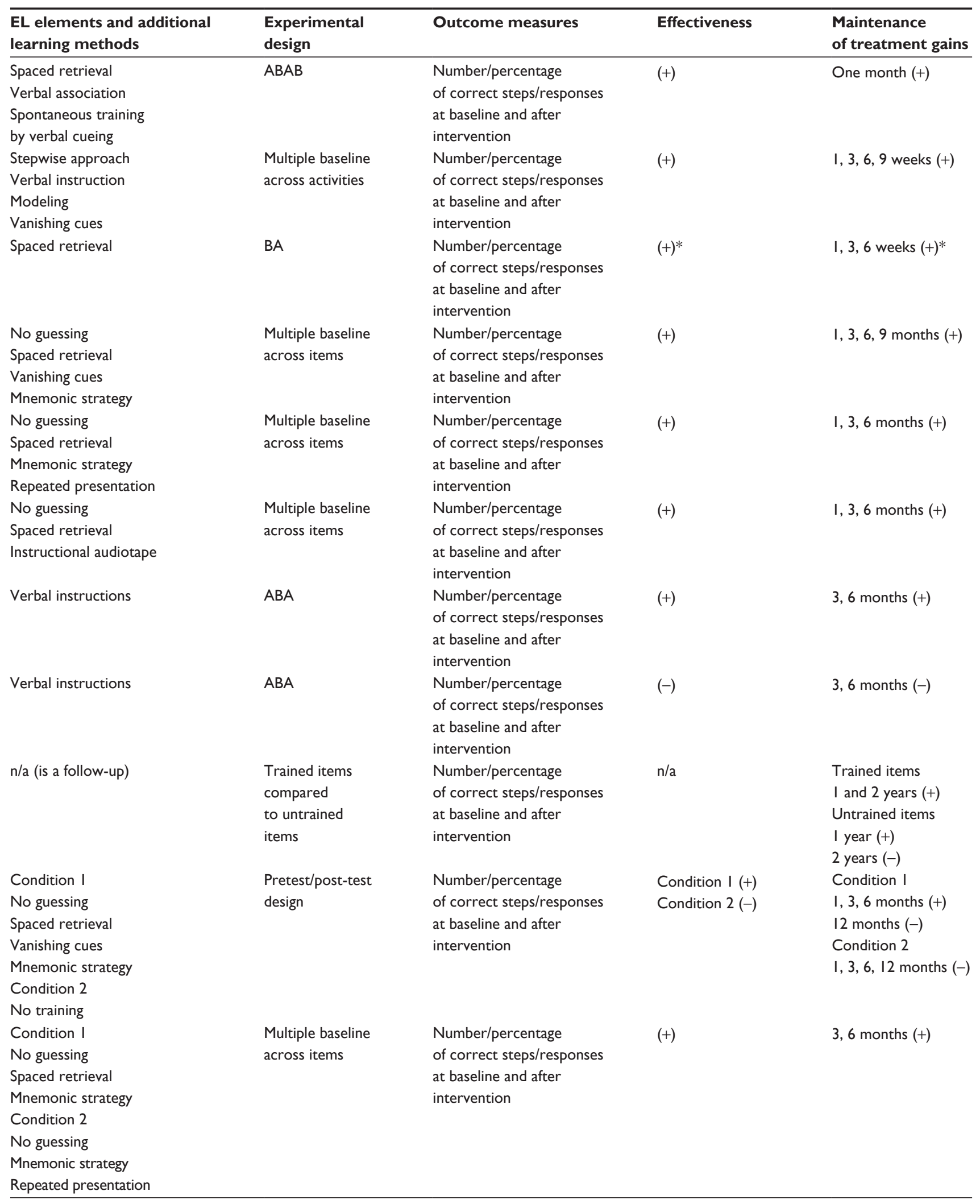


Table 2 (Continued)

\begin{tabular}{|c|c|c|c|c|c|c|}
\hline Study & $\mathbf{n}$ & $\begin{array}{l}\text { MMSE } \\
\text { score }\end{array}$ & $\begin{array}{l}\text { Dementia type } \\
\text { and severity }\end{array}$ & Task type and novelty & $\begin{array}{l}\text { Training intensity: } \\
\text { duration and frequency }\end{array}$ & $\begin{array}{l}\text { Training } \\
\text { location }\end{array}$ \\
\hline \multirow[t]{2}{*}{ Dechamps et $\mathrm{al}^{33}$} & 14 & $10-26$ & Minimal to & IADL task & 30 minutes & At home \\
\hline & & & moderate AD & Familiar & 6 sessions within one week & \\
\hline
\end{tabular}

$\begin{array}{lllll}\text { Jokel and } & 7 & 23-29 & \text { Minimal to } & \text { Names of objects } \\ \text { Anderson }^{40} & & & \text { mild SD } & \text { Familiar }\end{array}$

Each set: 2.5 hours Each set: Two or three times a week (total I2)

\begin{tabular}{|c|c|c|c|c|c|c|}
\hline Lekeu et $\mathrm{al}^{36}$ & 2 & 21 and 22 & Mild AD & $\begin{array}{l}\text { Use of a mobile telephone } \\
\text { Unknown }\end{array}$ & $\begin{array}{l}45 \text { minutes } \\
\text { Once or twice a week } \\
\text { (total } 13 / 14 \text { ) }\end{array}$ & Unknown \\
\hline $\begin{array}{l}\text { Metzler-Baddeley } \\
\text { and Snowden }\end{array}$ & 2 & $\mathrm{II}$ and 26 & $\begin{array}{l}\text { Minimal } \\
\text { and moderate } \\
\text { AD }\end{array}$ & $\begin{array}{l}\text { Names of objects } \\
\text { Familiar }\end{array}$ & $\begin{array}{l}\text { Unclear } \\
\text { Each set three times daily } \\
\text { for } 8 \text { days (total } 24 \text { ) }\end{array}$ & $\begin{array}{l}\text { At home } \\
\text { and in the } \\
\text { hospital }\end{array}$ \\
\hline Noonan et $\mathrm{al}^{38}$ & 8 & $9-24$ & $\begin{array}{l}\text { Minimal to } \\
\text { severe } A D\end{array}$ & $\begin{array}{l}\text { Names of objects } \\
\text { Familiar }\end{array}$ & $\begin{array}{l}\text { 40-60 minutes } \\
\text { Twice a week for } 5 \text { weeks } \\
\text { (total } 10 \text { ) }\end{array}$ & Unknown \\
\hline Provencher et $\mathrm{al}^{30}$ & I & 24 & Minimal AD & $\begin{array}{l}\text { Route learning } \\
\text { Unknown }\end{array}$ & $\begin{array}{l}30 \text { minutes } \\
14 \text { weeks (total I7) }\end{array}$ & Unknown \\
\hline Robinson et $\mathrm{al}^{39}$ & I & 26 & Minimal SD & $\begin{array}{l}\text { Names, definitions, and the } \\
\text { use of objects } \\
\text { Familiar }\end{array}$ & $\begin{array}{l}\text { Unclear } \\
\text { Twice a week for } 3 \text { weeks } \\
\text { (total 6) and once daily } \\
\text { using DVD }\end{array}$ & Unknown \\
\hline
\end{tabular}




\begin{tabular}{|c|c|c|c|c|}
\hline $\begin{array}{l}\text { EL elements and additional } \\
\text { learning methods }\end{array}$ & $\begin{array}{l}\text { Experimental } \\
\text { design }\end{array}$ & Outcome measures & Effectiveness & $\begin{array}{l}\text { Maintenance } \\
\text { of treatment gains }\end{array}$ \\
\hline Condition I & Within-subject & Number/percentage & Condition I (++) & I week \\
\hline Stepwise approach & & of correct steps/responses & Condition $2(++)$ & Condition I (++) \\
\hline Verbal instruction & & at baseline and after & Condition $3(+)$ & Condition $2(++)$ \\
\hline Visual instruction & & intervention & & Condition $3(+)$ \\
\hline Condition 2 & & & & 3 weeks \\
\hline Stepwise approach & & & & Condition I (++) \\
\hline Modeling & & & & Condition $2(++)$ \\
\hline Condition 3 & & & & Condition $3(-)$ \\
\hline \multicolumn{5}{|l|}{ Stepwise approach } \\
\hline \multicolumn{5}{|l|}{ Trial and error } \\
\hline EL, passive & Within-subject & Number/percentage & EL condition $(++)$ & I month \\
\hline Verbal instruction & & of correct steps/responses & EF condition $(+)$ & EL condition $(++)$ \\
\hline EL, active & & at baseline and after & & EF condition $(+)$ \\
\hline No guessing & & intervention & & 3 months \\
\hline Verbal cues & & & & EL condition $(+)$ \\
\hline EF, passive & & & & EF condition (+) \\
\hline \multicolumn{5}{|l|}{ Guessing allowed } \\
\hline \multicolumn{5}{|l|}{ Verbal cues } \\
\hline \multicolumn{5}{|l|}{ EF, active } \\
\hline \multicolumn{5}{|l|}{ Guessing allowed } \\
\hline \multicolumn{5}{|l|}{ Asking open ended questions } \\
\hline Stepwise approach & $A B A$ & Number/percentage & $(+)^{*}$ & $\mathrm{n} / \mathrm{a}$ \\
\hline Visual instruction & & of correct steps/responses & & \\
\hline Modeling & & at baseline and after & & \\
\hline Spaced retrieval & & intervention & & \\
\hline EL condition & Within-subject & Number/percentage & EL condition $(+)$ & $\mathrm{n} / \mathrm{a}$ \\
\hline No guessing & & of correct steps/responses & EF condition $(+)$ & \\
\hline Mnemonic strategy & & at baseline and after & & \\
\hline EF condition & & intervention & & \\
\hline \multicolumn{5}{|l|}{ Guessing allowed } \\
\hline \multicolumn{5}{|l|}{ Mnemonic strategy } \\
\hline EL condition & Within-subject & Number/percentage & I week & 5 weeks \\
\hline Verbal instructions & & of correct steps/responses & EL condition $(++)$ & EL condition $(++)$ \\
\hline Visual instructions & & at baseline and after & EF condition $(++)$ & EF condition $(++)$ \\
\hline EF condition & & intervention & No treatment $(+)$ & No treatment $(+)$ \\
\hline \multicolumn{5}{|l|}{ Cueing } \\
\hline \multicolumn{5}{|l|}{ No treatment condition } \\
\hline Stepwise approach & Multiple baseline & Number/percentage & $(+)$ & 10 weeks $(+)$ \\
\hline Modeling & across routes & of correct steps/responses & & \\
\hline Vanishing cues & & at baseline and after & & \\
\hline Verbal cues & & intervention & & \\
\hline Condition I & $A B A$ & Number/percentage & 3 days & I month \\
\hline Modeling & & of correct steps/responses & Condition I & Condition I \\
\hline Verbal instruction & & at baseline and after & Object naming $(+)$ & Object naming $(+)$ \\
\hline Condition 2 & & intervention & Definition $(+)$ & Definition $(+)$ \\
\hline \multirow[t]{5}{*}{ No training } & & & Use $(+)$ & Use $(+)$ \\
\hline & & & Condition 2 & Condition 2 \\
\hline & & & Object naming $(-)$ & Object naming $(-)$ \\
\hline & & & Definition (-) & Definition (-) \\
\hline & & & Use (-) & Use $(-)$ \\
\hline
\end{tabular}


Table 2 (Continued)

\begin{tabular}{|c|c|c|c|c|c|c|}
\hline Study & $\mathbf{n}$ & $\begin{array}{l}\text { MMSE } \\
\text { score }\end{array}$ & $\begin{array}{l}\text { Dementia type } \\
\text { and severity }\end{array}$ & Task type and novelty & $\begin{array}{l}\text { Training intensity: } \\
\text { duration and frequency }\end{array}$ & $\begin{array}{l}\text { Training } \\
\text { location }\end{array}$ \\
\hline Robinson et $\mathrm{al}^{39}$ & $\mathrm{I}$ & 22 & Mild SD & $\begin{array}{l}\text { Names, definitions, and the } \\
\text { use of objects } \\
\text { Familiar }\end{array}$ & $\begin{array}{l}\text { Unclear } \\
\text { Twice a week for } 2 \text { weeks } \\
\text { (total } 4 \text { ) and once daily } \\
\text { using DVD }\end{array}$ & Unknown \\
\hline Thivierge et $\mathrm{al}^{31}$ & I & 19 & Mild AD & $\begin{array}{l}\text { Using voice mail } \\
\text { Familiar }\end{array}$ & $\begin{array}{l}45 \text { minutes-I hour } \\
\text { Twice a week for } 4 \text { weeks } \\
\text { (total } 8 \text { ) }\end{array}$ & Unknown \\
\hline Thivierge et $\mathrm{al}^{31}$ & I & 25 & Minimal AD & $\begin{array}{l}\text { Use of an answering machine } \\
\text { Familiar }\end{array}$ & $\begin{array}{l}45 \text { minutes-I hour } \\
\text { Twice a week for } 4 \text { weeks } \\
\text { (total } 8 \text { ) }\end{array}$ & Unknown \\
\hline van Tilborg et $\mathrm{al}^{4 !}$ & $\begin{array}{l}10 \\
16\end{array}$ & $\begin{array}{l}15-26 \\
-\end{array}$ & $\begin{array}{l}\text { Minimal } \\
\text { to moderate } \\
\text { dementia } \\
\text { Healthy elderly }\end{array}$ & $\begin{array}{l}\text { Use of a microwave } \\
\text { and a coffee maker } \\
\text { New }\end{array}$ & $\begin{array}{l}\text { I } 5 \text { minutes } \\
5 \text { sessions within one week }\end{array}$ & Unknown \\
\hline Yamaguchi et $\mathrm{al}^{37}$ & $\begin{array}{l}2 \\
2\end{array}$ & $\begin{array}{l}22 \text { and } 23 \\
-\end{array}$ & $\begin{array}{l}\text { Mild AD } \\
\text { Healthy elderly }\end{array}$ & $\begin{array}{l}\text { Virtually preparing two slices } \\
\text { of bread and virtually preparing } \\
\text { a cup of coffee } \\
\text { Familiar }\end{array}$ & $\begin{array}{l}20 \text { minutes } \\
\text { One session of } \\
6 \times 20 \text { minutes }\end{array}$ & Unknown \\
\hline
\end{tabular}

Note: ${ }^{*}$ No $P$-values available.

Abbreviations: $n$, number of participants; IADL, instrumental activities of daily living; MMSE, Mini-Mental State Examination; AD, Alzheimer dementia; SD, semantic dementia; EL, errorless learning; EF, errorful learning; n/a, not applicable; $(+)$, significant effect; $(+)$, significant effect versus baseline and other learning conditions; $(-)$, nonsignificant effect.

Results section. Results for each of the studies are presented in Table 2.

\section{Dementia type and severity}

In total, 70 (older) adults with dementia participated in the various intervention studies. Most of the participants had Alzheimer's disease (21 studies) ${ }^{27-38}$ and severity varied between minimal, mild, and moderate. In three studies, participants had minimal to mild semantic dementia. ${ }^{39,40}$ In one study, the etiology of the cognitive deficits was unknown for most patients due to the lack of biomarkers (with a high likelihood that the dementia in most of the participants resulted from Alzheimer's disease). ${ }^{41}$

\section{Task type and novelty}

Most studies focused on teaching participants the use of devices such as a mobile phone, answering machine, coffee maker, or microwave..$^{28,31,33,34,36,41}$ Participants also practiced face-name associations of familiar people, such as family members or members of a social club, ${ }^{27,29,34,35}$ and orientation skills, ${ }^{28,30,34}$ such as the use of a calendar and directions (routes). Relearning the names of everyday objects was practiced in six studies. ${ }^{32,38-40}$ Only six studies described in detail the grounds for selecting the particular activities, that is, after carefully interviewing the participant and his or her primary caregiver. ${ }^{27-29,33}$

In the majority of studies, the participants relearned familiar but forgotten tasks or information..$^{28,31-35,37-40}$ In two studies, novel tasks were learned, ${ }^{28,41}$ while seven studies provided no information on this aspect. . $7,29,30,34,36^{2}$

\section{Training intensity and training location}

Overall, the intensity of training varied considerably between the studies reviewed (see Table 2). The number and/or dura- 


\begin{tabular}{|c|c|c|c|c|}
\hline $\begin{array}{l}\text { EL elements and additional } \\
\text { learning methods }\end{array}$ & $\begin{array}{l}\text { Experimental } \\
\text { design }\end{array}$ & Outcome measures & Effectiveness & $\begin{array}{l}\text { Maintenance } \\
\text { of treatment gains }\end{array}$ \\
\hline Condition I & $A B A$ & Number/percentage & 3 days & I month \\
\hline Modeling & & of correct steps/responses & Condition I & Condition I \\
\hline Verbal instruction & & at baseline and after & Object naming $(-)$ & Object naming (-) \\
\hline Condition 2 & & intervention & Definition $(+)$ & Definition (-) \\
\hline \multirow[t]{5}{*}{ No training } & & & Use $(+)$ & Use $(-)$ \\
\hline & & & Condition 2 & Condition 2 \\
\hline & & & Object naming $(-)$ & Object naming (-) \\
\hline & & & Definition $(+)$ & Definition (-) \\
\hline & & & Use (-) & Use $(-)$ \\
\hline Stepwise approach & Multiple baseline & Number/percentage & $(+)$ & $I$ and 5 weeks $(+)$ \\
\hline Modeling & across subjects & of correct steps/responses & & \\
\hline Verbal instructions & & at baseline and after & & \\
\hline Spaced retrieval & & intervention & & \\
\hline \multicolumn{5}{|l|}{ Vanishing cues } \\
\hline Stepwise approach & Multiple baseline & Number/percentage & $(+)$ & $\mathrm{I}$ and 5 weeks $(+)$ \\
\hline Modeling & across subjects & of correct steps/responses & & \\
\hline Verbal instructions & & at baseline and after & & \\
\hline Spaced retrieval & & intervention & & \\
\hline \multicolumn{5}{|l|}{ Vanishing cues } \\
\hline EL condition I & Counter-balanced & Number/percentage & EL condition I (+) & $7-10$ days \\
\hline Stepwise approach & self-controlled & of correct steps/responses & EL condition $2(+)$ & EL condition I (+) \\
\hline Verbal instruction & cases & at baseline and after & & EL condition $2(-)$ \\
\hline EL condition 2 & & intervention & & \\
\hline \multicolumn{5}{|l|}{ Stepwise approach } \\
\hline \multicolumn{5}{|l|}{ Modeling } \\
\hline EL condition I & Mixed factorial & Number/percentage & EL condition I $(+)^{*}$ & $\mathrm{n} / \mathrm{a}$ \\
\hline Stepwise approach & design between & of correct steps/responses & EL condition $2(+)^{*}$ & \\
\hline Verbal instructions & two single cases & at baseline and after & & \\
\hline Visual instruction & & intervention & & \\
\hline \multicolumn{5}{|l|}{ EL condition 2} \\
\hline \multicolumn{5}{|l|}{ Stepwise approach } \\
\hline Visual instructions & & & & \\
\hline
\end{tabular}

tion of training sessions was not always specified in all studies. ${ }^{27-29,32,34,35,39}$ Half of the studies gave complete and detailed information about their duration and frequency, ${ }^{28,30,31,33,36-38,40,41}$ while five did not provide any information on either aspect. ${ }^{29,34}$ In six studies, the duration of training was unclear. ${ }^{27,32,35,39}$ Training took place every week and in half of the studies at least twice a week, ${ }^{27,28,31,32,36,38-40}$ with sessions lasting between 30 minutes and 1.5 hours in most studies..$^{28,30,31,33,36,38}$ However, the total number of sessions varied among the tasks trained (see Table 2). In nine studies, training comprised fewer than ten sessions, ${ }^{31,33,35,37,39,41}$ while in ten studies, participants attended ten sessions or more. ${ }^{27,28,30,32,36,38,40}$ Moreover, four studies promoted additional practice in the home environment, ${ }^{27,29,34,35}$ one by involving the spouse as a cotherapist ${ }^{32}$ and one by using a DVD of the therapy sessions. ${ }^{39}$ Most studies did not mention where the training took place. ${ }^{29-31,34-41}$
Five studies explicitly mentioned that the training was performed at home,,$^{27,28,33}$ and in two studies, the training took place both in the hospital and at home. ${ }^{32}$

\section{Errorless learning elements}

EL can consist of a variety of instructions and task adaptations, which in the intervention studies reviewed were combined in various ways: participants were encouraged not to guess the correct response, ${ }^{27,29,32,34,35,40}$ a stepwise approach, ${ }^{28,30,31,33,36,41}$ the therapist modeled the task steps, ${ }^{28,30,31,33,36,39,41}$ and finally, to guide task performance,

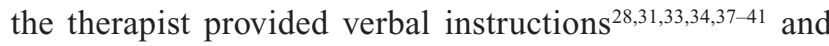
visual instructions (ie, a written action plan or/and pictures of the actions). ${ }^{33,36-38}$ In all studies, the EL elements were used during the acquisition phase or during the repetition of the task steps. 
To facilitate retrieval of task information and to rehearse action sequences, two other teaching techniques were frequently applied, ie, spaced retrieval and vanishing cues. Spaced retrieval was offered in 11 studies used in combination with visual instructions, a stepwise approach, verbal instruction, and/ or modeling. ${ }^{27-29,31,34-36}$ The vanishing cues method was applied in six studies, ${ }^{27,28,30,31,35}$ with four using a combination of vanishing cues and spaced retrieval, ${ }^{27,31,35}$ and four (also) combining vanishing cues with modeling, verbal instruction, and a stepwise approach. ${ }^{28,30,31}$ In all these studies, cues were gradually withheld in such a way that eventually participants were able to perform the tasks autonomously and unprompted.

Although EL aims to reduce errors during the acquisition and retrieval of information, errors may nevertheless occur during training. In these instances, the therapist should correct the error immediately. Thus, in the case of the vanishing cues method, renewed cues were provided by the therapist when errors occurred. ${ }^{30,31,36}$ If errors occurred during spaced retrieval, the correct answer was offered, after which the former (shorter) interval was reinstated $28,29,31$ or the interval was reduced by half..$^{27,35,36}$ Fourteen studies did not specify whether or how errors were corrected ${ }^{28,32-34,37,38,40,41}$ and in two studies no errors were made. ${ }^{39}$

\section{Experimental design and outcome measures}

As to experimental designs, we identified five group studies, ${ }^{33,35,38,40,41}$ with four comparing an EL approach with a no-treatment condition, or an EF condition in a counterbalanced within-subject design. ${ }^{33,35,38,40}$ Noonan et $\mathrm{al}^{38}$ applied a within-subject design to compare EL with EF and a notreatment condition, analyzing the data at group level and at participant level. In another study ${ }^{41}$ between-groups and within-group variances were computed in two conditions that will both be considered EL-type learning in this review. In ten articles, 20 single-case studies were described. Eight of these had multiple-baseline designs across items or behaviors and across subjects. ${ }^{27-31,34}$ Six studies applied an ABA design, ${ }^{34,36,39}$ one study an ABAB reversal design, ${ }^{28}$ and one study a BA design. ${ }^{28}$ Two case studies examined the performance of two patients in both an EL and an EF condition, with the order of learning conditions and the task trained in each condition being counterbalanced..$^{32}$ Yamaguchi et al ${ }^{37}$ employed a multiple-case study design including two healthy elderly patients and two patients with Alzheimer's disease. A single-case study with a multiple-baseline design has higher internal validity than a single-case study using a pre-to-post test design and thus provides more convincing evidence.
All studies used either the number or the percentage of correctly executed steps as their primary outcome measure or the number of correct responses given at the baseline and post-intervention assessments. ${ }^{26-41}$ Twelve studies $^{27,28,30,31,33,36,40,41}$ reported the number of correct steps executed or correct responses given during the intervention, while three studies scored every response according to the degree of assistance the participant required to perform the task independently. ${ }^{31,33}$

\section{Effectiveness and maintenance of treatment gains}

Seventeen of the 25 studies demonstrated a statistically significant superior effect of EL immediately after training compared with EF or a no-treatment condition. ${ }^{27-31,33-35,38-41}$ One of these studies obtained a significant group-level effect, with not all participants showing an EL benefit. ${ }^{35}$ Robinson et $\mathrm{al}^{39}$ found that only some aspects of the tasks trained culminated in statistically significant effects. In five other studies, performance levels improved after EL, but no $P$-values were reported. ${ }^{28,36,37}$ Two studies found no differences between $\mathrm{EL}$ and $\mathrm{EF}^{32}$ and Clare et $\mathrm{al}^{34}$ found no beneficial effects of EL. Taken together, evidence of a statistically significant superior effect of EL was reported in five group studies, eight multiple-baseline studies, one study using an $\mathrm{ABAB}$ design, and three studies using an ABA design.

To examine whether the EL effects were preserved over time, 20 of the 26 studies carried out follow-up evaluations, 17 of which showed maintenance of EL effects after one week up to 9 months (see Table 2). ${ }^{26-31,33-35,38,40,41}$ The time span between the post-intervention and the follow-up assessments varied considerably, ie, between one and 3 weeks in seven studies, ${ }^{28,31,33,38,41}$ and one month or more (with the longest follow-up interval lasting up to 2 years) in 18 studies. ${ }^{26-31,34,35,38-40}$ Some studies conducted repeated follow-up assessments, eg, every 3 weeks ${ }^{28,33}$ or every 3 months. ${ }^{27,29,34,35,40}$

In 13 of the studies reporting positive follow-up results, participants did not continue to practice the tasks between intervention cessation and follow-up, ${ }^{26,28,30,31,33,34,38,40,41}$ although in two of these studies participants were exposed to the trained task every day (without actually retraining it), 28,30 with Provencher et $\mathrm{al}^{30}$ recording a significant improvement in performance over time. Comparing EL and EF, another study showed an advantage for EL after one month, but not after 3 months, although the overall gains were maintained to a significant degree..$^{40}$ Van Tilborg et $\mathrm{l}^{41}$ found a sustained EL effect for only one of the two tasks trained. 
In four studies, participants attended one or more refresher sessions during the follow-up interval, resulting in positive effects. ${ }^{27,29,31,35}$ In these refresher sessions, the task was practiced again adhering to the EL procedure adopted during the intervention. Three of the four studies, however, failed to describe their number and duration in detail. ${ }^{27,29,35}$ One of the studies offering refresher sessions even reported treatment effects 6 months after training. ${ }^{35}$ After one year performance had declined, remaining, however, above baseline level. Regrettably, the study does not detail refresher training intensity.

\section{Discussion}

The results of our review of 26 studies applying principles of EL show that people with minimal to moderate dementias can (re)learn meaningful daily life skills or relevant knowledge using an error-reducing teaching approach. Five controlled group studies and 12 single-case studies obtained significantly superior effects using EL. Another five (preliminary) studies also reported benefits, but had not run statistical analyses on their data, rendering the conclusions as to EL effectiveness equivocal. Notably, a considerable number of the studies we reviewed included follow-up assessments, showing that effects were preserved over time, even weeks or months after the training had ended. Based on these findings, EL appears to be a promising principle to teaching (older) adults with compromised memory and executive functions due to neurodegenerative syndromes to (re)gain relevant daily life skills, fostering their confidence and self-reliance.

The results extend those reported in previous EL efficacy studies in which various patient populations learned to master different kinds of laboratory tasks, such as arbitrary face-name associations and word lists. ${ }^{8,42-44}$ Although, in their review, Grandmaison and Simard ${ }^{16}$ had earlier shown that cognitive rehabilitation programs for patients with dementia may benefit from error-reducing principles, the merit of the current review is that it demonstrates the beneficial effects of EL on meaningful, everyday tasks, thereby establishing its suitability and feasibility for implementation in clinical practice for dementia care. As also evident from our review, despite the progressive nature of dementias, the effects are long-lasting, being maintained for at least 1-3 weeks.

The mounting evidence that individuals with dementia are still able to acquire new, or regain forgotten skills and knowledge, is important for professionals working in dementia care, since errorless principles in training meaningful skills may offer new opportunities for interventions aimed at people with dementia. When patients are encouraged to (re) learn meaningful daily activities in the early stages of their dementia, they may be enabled to step up their activity levels, fostering their sense of competence, potentially resulting in a higher degree of independence, and ultimately improving their quality of life. ${ }^{45}$ Moreover, it can help people with dementia to function, with assistance and support, longer in their home environment. Furthermore, as the underlying principle of EL is preventing errors, this implies success for the patient in every training session, which helps create positive memories during learning, furthering the consolidation and retrieval of information, and improving mood. ${ }^{46}$

The effectiveness of EL has been investigated and confirmed in a multitude of tasks involving relevant daily life activities and skills, such as the use of electronic devices and household appliances, orientation skills, face-name associations, and definitions and uses of objects. It has been suggested that EL is most successful in tasks that have an implicit procedural learning aspect to them. ${ }^{13}$ However, our review shows that EL is effective in both procedural and nonprocedural tasks. Further, EL benefits were found to be most pronounced in the early stage of the disease, when progression is relatively slow and impairments in other cognitive domains are still mild. Although the studies we reviewed did not explicitly include patients with mild cognitive impairment, MMSE scores for participants in the minimally severe groups show overlap with those typically found in individuals diagnosed with mild cognitive impairment. ${ }^{47}$ Thus, EL may also be effective in teaching people with mild cognitive impairment relevant daily life skills, as some studies have already shown. ${ }^{48,49}$ This is consistent with studies reporting large positive effects of EL in mild to moderate dementia, ${ }^{50,51}$ with smaller effects being reported in severe dementia. ${ }^{44}$ This is likely due to a decline in other nonmemory cognitive (eg, executive) functions in addition to a further decline in the memory domain. Nevertheless, future studies should examine whether EL may still be applicable in older adults with more severe dementias residing in nursing homes, given that some studies have reported positive effects in this population using selected tasks that were adjusted to the participants' performance levels. ${ }^{33}$

Our results additionally show that despite the differences in etiology, EL is effective in both Alzheimer's disease and semantic dementia. There are, of course, dementia-specific differences in memory dysfunction in that episodic memory is most impaired in Alzheimer's disease, while semantic memory deficits are most prominent in semantic dementia. Thus, while patients with semantic dementia may have a better preserved episodic learning capacity, they may still benefit from EL. In the studies reviewed, the difference between the two dementia types predominantly lies in the 
type of task being practiced. The study participants with semantic dementia mostly (re)learned nonprocedural tasks, whereas participants with Alzheimer's disease trained both procedural and nonprocedural tasks.

Notwithstanding the success of EL in helping persons with dementia (re)engage in meaningful (daily) activities, the question remains as to how EL principles can best be applied in clinical practice. Some of our recommendations follow from the results of our review. Obviously, the essence of EL is creating a learning environment in which it becomes difficult or impossible for a person with dementia to make errors. Based on our findings, we pose that, depending on the activity or skill to be trained, a combination of several error-reduction principles is likely to be most effective. More specifically, modeling and verbal instruction, in combination with a stepwise approach, were shown to be beneficial in the acquisition of procedural tasks. The vanishing cues technique was used effectively to systematically decrease the degree of assistance during the acquisition phase of both procedural and nonprocedural tasks. Spaced retrieval was applied successfully in tasks requiring acquisition of nonprocedural information, as in face-name associations, where asking people not to guess was also found to be relevant. Verbal instruction was applied in both procedural and nonprocedural tasks as well, where the therapist verbally guides clients through the task steps to prevent errors.

Training intensity also plays an important role in the success of EL. However, studies varied considerably in this respect, with not all studies providing detailed information. Training sessions were mostly delivered once or twice a week. Durations of each training session ranged from 20 minutes to 2.5 hours, with the number needed for successful task completion varying between six and 21 sessions. This diversity prevents firm conclusions from being drawn about the minimal intensity that is required for EL to produce a clinically relevant effect. Of course, training intensity also depends on dementia severity and the tasks to be (re)learned, as well as individual differences, eg, motivational or psychosocial factors and physical limitations. Individual training programs should therefore be tailored to each individual patient and the task at hand. Training may be based on goals rather than on a fixed number of sessions; for example, the patient needs to be able to perform the targeted activity three times successfully on two consecutive training days. One could consider involving the spouse or caregivers to support additional training in the patient's home environment. Given that EL training is often laborious and time-consuming, a therapeutic role of family members or carers can also contribute to the cost-effectiveness of the approach. ${ }^{27,29}$ Grandmaison and Simard ${ }^{16}$ concluded that a dyadic approach, in which caregivers help the patient apply various memory and cognitive improvement strategies, is one of the most promising approaches to the cognitive rehabilitation of patients with Alzheimer's disease. While EL enables family members or caregivers to engage actively and constructively in joint activities with their spouse or client, there is the risk that such a therapeutic role for family members or carers may potentially increase their care burden instead of reducing it. ${ }^{52}$ Care should be taken that health professionals remain the principal care provider guiding the actual learning process, where the caregiver can then help the patient train or maintain the newly learned skills in their home environment.

Because the studies we reviewed reported positive effects that were obtained in both institutional and domestic settings, they do not prompt specific recommendations on the optimal training site. However, it is known from studies in rehabilitation settings that in order to facilitate generalization, training locations and materials should bear as close a resemblance to the patients' experience and daily life as possible. ${ }^{53}$ To our knowledge, no research has been done to establish whether EL training at home yields better results than when training takes place elsewhere.

\section{Recommendations for future research}

Our search of the relevant literature produced a notable number of single-case studies, most with experimental designs ensuring good internal validity. Nevertheless, to reliably establish the effects of EL, study designs affording higher internal validity need to be applied in larger population samples. The five group studies included in our review all employed a control condition and randomization, but the number of participants was still relatively small $(n<15)$. Clearly, randomized controlled trials with sufficiently large samples are required to replicate the current results. Also, such randomized controlled trials should not only study the efficacy of EL, but also its effectiveness (see, eg, Voigt-Radloff et al ${ }^{54}$ ). Given that learning deficits may differ across dementia types due to different underlying etiologies and cognitive profiles, randomized controlled trials should include sufficiently large subsamples of different etiologies, allowing evaluation of EL effectiveness and applicability in the different types of dementias. They should also consider dementia severity to uncover at which stage of the disease EL is most effective. Moreover, it is important to examine systematically whether different types of tasks (procedural versus nonprocedural) benefit from different types or 
combinations of training principles, carefully specifying EL procedures and training intensity. Because these aspects were not always detailed in the papers we reviewed, we cannot make any recommendations in this respect. Evidently, future studies need to provide clear and detailed descriptions of the learning procedures employed, training intensity, duration and location(s), etiology, disease severity, and all other factors that may influence learning effects. Finally, the various studies compared the magnitude of correct responses at baseline, during and after the intervention, and at follow-up. None assessed changes beyond the ones measured on the tasks or skills trained. To monitor patients' overall level of (daily) functioning, observation rating scales from the field of occupational therapy could be used in addition to inventories gauging quality of life.

\section{Conclusion}

This review shows the effectiveness of EL in teaching people with different types of dementia meaningful activities of daily living. These learning gains are mostly maintained over a prolonged period of time, with or without refresher sessions. Positive effects are mostly studied and obtained in the early stages of dementia. Undeniably, people with dementia can still (re)acquire (some) useful skills and relevant daily life activities. Procedural tasks can best be trained using a stepwise approach, with the therapist modeling each step and providing verbal cues to guide the patient. Verbal instructions, spaced retrieval, and asking patients not to guess are most suitable for the acquisition of nonprocedural tasks. Vanishing cues are effective in steadily reducing the amount of help needed from the therapist and can be used in all task types. Training intensity and duration should be tailored to the needs of the individual patient and preferably take place in a familiar environment to facilitate acquisition.

EL helps build up activity levels, the motivation for undertaking new activities, and the sense of competence, which together may result in more autonomy, independence, and better quality of life for people with dementia. EL-based interventions provide health professionals with an opportunity to interact with their patients in a more positive way, focusing on residual abilities and learning capacities rather than deficits and decline. We hope that the insights gained from our review about the effectiveness and practical feasibility of EL can be used for developing a manual for clinical practice.

\section{Acknowledgments}

This research was supported by a grant from the Devon Foundation, the Netherlands. RPCK was supported by a grant from the National Initiative Brain and Cognition (056-11-011) as part of the "The Healthy Brain, Program Cognitive Rehabilitation" pillar.

\section{Disclosure}

The authors report no conflicts of interest in this work.

\section{References}

1. Viola LF, Nunes PV, Yassuda MS, et al. Effects of a multidisciplinary cognitive rehabilitation program for patients with mild Alzheimer's disease. Clinics (Sao Paulo). 2011;66(8):1395-1400.

2. De Vreese LP, Neri M, Fioravanti M, Belloi L, Zanetti O. Memory rehabilitation in Alzheimer's disease: a review of progress. Int J Geriatr Psychiatry. 2001;16(8):794-809.

3. Kurz A, Thone-Otto A, Cramer B, et al. CORDIAL: cognitive rehabilitation and cognitive-behavioral treatment for early dementia in Alzheimer disease: a multicenter, randomized, controlled trial. Alzheimer Dis Assoc Disord. 2012;26(3):246-253.

4. Clare L, Jones RS. Errorless learning in the rehabilitation of memory impairment: a critical review. Neuropsychol Rev. 2008;18(1):1-23.

5. Sitzer DI, Twamley EW, Jeste DV. Cognitive training in Alzheimer's disease: a meta-analysis of the literature. Acta Psychiatr Scand. 2006;114(2):75-90.

6. Terrace HS. Discrimination learning with and without "errors". J Exp Anal Behav. 1963;6:1-27.

7. Baddeley AD. Implicit memory and errorless learning: a link between cognitive theory and neuropsychological rehabilitation? In: Squire L, Butters N, editors. Neuropsychology of Memory. 2nd ed. New York, NY: Guilford Press; US; 1992.

8. Baddeley A, Wilson BA. When implicit learning fails: Amnesia and the problem of error elimination. Neuropsychologia. 1994;32(1):53-68.

9. Wilson BA, Baddeley A, Evans J, Shiel A. Errorless learning in the rehabilitation of memory-impaired people. Neuropsychol Rehabil. 1994;4(3):307-326.

10. Mount J, Pierce SR, Parker J, DiEgidio R, Woessner R, Spiegel L. Trial and error versus errorless learning of functional skills in patients with acute stroke. NeuroRehabilitation. 2007;22(2):123-132.

11. Middleton EL, Schwartz MF. Errorless learning in cognitive rehabilitation: a critical review. Neuropsychol Rehabil. 2012;22(2); $138-168$.

12. Komatsu S, Mimura M, Kato M, Wakamatsu N, Kashima H. Errorless and effortful processes involved in the learning of face-name associations by patients with alcoholic Korsakoff's syndrome. Neuropsychol Rehabil. 2000;10(2):113-132.

13. Evans JJ, Wilson BA, Schuri U, et al. A comparison of "errorless" and "trial-and-error" learning methods for teaching individuals with acquired memory deficits. Neuropsychol Rehabil. 2000;10(1):67-101.

14. Kessels RPC, de Haan EH. Implicit learning in memory rehabilitation: a meta-analysis on errorless learning and vanishing cues methods. $J$ Clin Exp Neuropsychol. 2003;25(6):805-814.

15. Mulholland CC, O’Donoghue D, Meenagh C, Rushe TM. Errorless learning and memory performance in schizophrenia. Psychiatry Res. 2008;159(1-2):180-188.

16. Grandmaison E, Simard M. A critical review of memory stimulation programs in Alzheimer's disease. $J$ Neuropsychiatry Clin Neurosci. 2003;15(2):130-144.

17. American Psychiatric Association. Diagnostic and Statistical Manual of Mental Disorders, 4th ed, Text Revision. Washington, DC: American Psychiatric Association; 2000.

18. McKhann GM, Knopman DS, Chertkow H, et al. The diagnosis of dementia due to Alzheimer's disease: recommendations from the National Institute on Aging-Alzheimer's Association workgroups on diagnostic guidelines for Alzheimer's disease. Alzheimers Dement. 2011;7(3):263-269. 
19. Roman GC, Tatemichi TK, Erkinjuntti T, et al. Vascular dementia: diagnostic criteria for research studies. Report of the NINDS-AIREN International Workshop. Neurology. 1993;43(2):250-260.

20. Neary D, Snowden JS, Gustafson L, et al. Frontotemporal lobar degeneration: a consensus on clinical diagnostic criteria. Neurology. 1998;51(6):1546-1554.

21. Gorno-Tempini ML, Hillis AE, Weintraub S, et al. Classification of primary progressive aphasia and its variants. Neurology. 2011;76(11): 1006-1014.

22. Rascovsky K, Hodges JR, Knopman D, et al. Sensitivity of revised diagnostic criteria for the behavioural variant of frontotemporal dementia. Brain. 2011;134(Pt 9):2456-2477.

23. Folstein MF, Folstein SE, McHugh PR. "Mini-mental state". A practical method for grading the cognitive state of patients for the clinician. J Psychiatr Res. 1975;12(3):189-198.

24. Greene JD, Hodges JR, Baddeley AD. Autobiographical memory and executive function in early dementia of Alzheimer type. Neuropsychologia. 1995;33(12):1647-1670.

25. Hodges JR, Patterson K. Is semantic memory consistently impaired early in the course of Alzheimer's disease? Neuroanatomical and diagnostic implications. Neuropsychologia. 1995;33(4):441-459.

26. Clare L, Wilson BA, Carter G, Hodges JR, Adams M. Long-term maintenance of treatment gains following a cognitive rehabilitation intervention in early dementia of Alzheimer type: a single case study. Neuropsychol Rehabil. 2001;11(3-4):477-494.

27. Clare L, Wilson BA, Breen K, Hodges JR. Errorless learning of face-name associations in early Alzheimer's disease. Neurocase. 1999;5(1):37-46.

28. Bier N, Provencher V, Gagnon L, Van der Linden M, Adam S, Desrosiers J. New learning in dementia: transfer and spontaneous use of learning in everyday life functioning. Two case studies. Neuropsychol Rehabil. 2008;18(2):204-235.

29. Clare L, Wilson BA, Carter G, Hodges JR. Cognitive rehabilitation as a component of early intervention in Alzheimer's disease: a single case study. Aging Ment Health. 2003;7(1):15-21.

30. Provencher V, Bier N, Audet T, Gagnon L. Errorless-based techniques can improve route finding in early Alzheimer's disease: a case study. Am J Alzheimers Dis Other Demen. 2008;23(1):47-56.

31. Thivierge S, Simard M, Jean L, Grandmaison E. Errorless learning and spaced retrieval techniques to relearn instrumental activities of daily living in mild Alzheimer's disease: a case report study. Neuropsychiatr Dis Treat. 2008;4(5):987-999.

32. Metzler-Baddeley C, Snowden JS. Brief report: errorless versus errorful learning as a memory rehabilitation approach in Alzheimer's Disease. J Clin Exp Neuropsychol. 2005;27(8):1070-1079.

33. Dechamps A, Fasotti L, Jungheim J, et al. Effects of different learning methods for instrumental activities of daily living in patients with Alzheimer's dementia: a pilot study. Am JAlzheimers Dis Other Demen. 2011;26(4):273-281.

34. Clare L, Wilson BA, Carter G, Breen K, Gosses A, Hodges JR. Intervening with everyday memory problems in dementia of Alzheimer type: an errorless learning approach. J Clin Exp Neuropsychol. 2000;22(1):132-146.

35. Clare L, Wilson BA, Carter G, Roth I, Hodges JR. Relearning facename associations in early Alzheimer's disease. Neuropsychology. 2002;16(4):538-547.

36. Lekeu F, Wojtasik V, Van der Linden M, Salmon E. Training early Alzheimer patients to use a mobile phone. Acta Neurol Belg. 2002;102(3):114-121.

\section{Clinical Interventions in Aging}

\section{Publish your work in this journal}

Clinical Interventions in Aging is an international, peer-reviewed journal focusing on evidence-based reports on the value or lack thereof of treatments intended to prevent or delay the onset of maladaptive correlates of aging in human beings. This journal is indexed on PubMed Central, MedLine, the American Chemical Society's 'Chemical Abstracts
37. Yamaguchi T, Foloppe DA, Richard P, Richard E, Allain P. A dualmodel virtual reality kitchen for (re)learning of everyday cooking activities in Alzheimer's disease. Presence. 2012;21(1):43-57.

38. Noonan KA, Pryer LR, Jones RW, Burns AS, Lambon Ralph MA. A direct comparison of errorless and errorful therapy for object name relearning in Alzheimer's disease. Neuropsychol Rehabil. 2012;22(2): 215-234.

39. Robinson S, Druks J, Hodges J, Garrard P. The treatment of object naming, definition, and object use in semantic dementia: the effectiveness of errorless learning. Aphasiology. 2009;23(6):749-775.

40. Jokel R, Anderson ND. Quest for the best: effects of errorless and active encoding on word re-learning in semantic dementia. Neuropsychol Rehabil. 2012;22(2):187-214.

41. van Tilborg IA, Kessels RPC, Hulstijn W. How should we teach everyday skills in dementia? A controlled study comparing implicit and explicit training methods. Clin Rehabil. 2011;25(7):638-648.

42. Hunkin NM, Squires EJ, Parkin AJ, Tidy JA. Are the benefits of errorless learning dependent on implicit memory? Neuropsychologia. 1998;36(1):25-36.

43. Haslam C, Gilroy D, Black S, Beesley T. How successful is errorless learning in supporting memory for high and low-level knowledge in dementia? Neuropsychol Rehabil. 2006;16(5):505-536.

44. Ruis C, Kessels RPC. Effects of errorless and errorful face-name associative learning in moderate to severe dementia. Aging Clin Exp Res. 2005;17(6):514-517.

45. Cohen M, Ylvisaker M, Hamilton J, Kemp L, Claiman B. Errorless learning of functional life skills in an individual with three aetiologies of severe memory and executive function impairment. Neuropsychol Rehabil. 2010;20(3):355-376.

46. Kensinger EA. Remembering emotional experiences: the contribution of valence and arousal. Rev Neurosci. 2004;15(4):241-251.

47. Petersen RC. Mild cognitive impairment as a diagnostic entity. J Intern Med. 2004;256(3):183-194

48. Akhtar S, Moulin CJ, Bowie PC. Are people with mild cognitive impairment aware of the benefits of errorless learning? Neuropsychol Rehabil. 2006;16(3):329-346.

49. Jean L, Simard M, van Reekum R, Bergeron ME. Towards a cognitive stimulation program using an errorless learning paradigm in amnestic mild cognitive impairment. Neuropsychiatr Dis Treat. 2007;3(6): 975-985.

50. Zanetti O, Zanieri G, Di Giovanni G, et al. Effectiveness of procedural memory stimulation in mild Alzheimer's disease patients: a controlled study. Neuropsychol Rehabil. 2001;11(3-4):263-272.

51. Kessels RPC, Olde Hensken LM. Effects of errorless skill learning in people with mild-to-moderate or severe dementia: a randomized controlled pilot study. NeuroRehabilitation. 2009;25(4):307-312.

52. Bruce JM, McQuiggan M, Williams V, Westervelt H, Tremont G. Burden among spousal and child caregivers of patients with mild cognitive impairment. Dement Geriatr Cogn Disord. 2008;25(4): 385-390.

53. Geusgens CA, Winkens I, van Heugten CM, Jolles J, van den Heuvel WJ. Occurrence and measurement of transfer in cognitive rehabilitation: a critical review. J Rehabil Med. 2007;39(6):425-439.

54. Voigt-Radloff S, Leonhart R, Olde Rikkert MG, Kessels RPC, Hüll M. Study protocol of the multi-site randomised controlled REDALI-DEM trial - the effects of structured relearning methods on daily living task performance of persons with dementia. BMC Geriatr. 2011;11:44.

\section{Dovepress}

Service' (CAS), Scopus and the Elsevier Bibliographic databases. The manuscript management system is completely online and includes a very quick and fair peer-review system, which is all easy to use. Visit $\mathrm{http}: / / \mathrm{www}$.dovepress.com/testimonials.php to read real quotes from published authors. 